\title{
Fine Structure of the Gas Bladder of Alligator Gar, Atractosteus spatula
}

\author{
Ahmad Omar-Ali ${ }^{1}$, Wes Baumgartner ${ }^{2}$, Peter J. Allen ${ }^{3}$, Lora Petrie-Hanson ${ }^{1 *}$ \\ ${ }^{1}$ Department of Basic Sciences, College of Veterinary Medicine, Mississippi State University, Mississippi State, MS 39762, USA \\ ${ }^{2}$ Department of Pathobiology and Population Medicine, College of Veterinary Medicine, Mississippi State University, Mississippi State, MS 39762, USA \\ ${ }^{3}$ Department of Wildlife, Fisheries and Aquaculture, College of Forest Resources, Mississippi State University, Mississippi State, MS 39762, USA
}

Received: 1 November, 2016; Accepted: 2 December, 2016 ; Published: 12 December, 2016

*Corresponding author: Lora Petrie-Hanson, Associate Professor, College of Veterinary Medicine, 240 Wise Center Drive PO Box 6100, Mississippi State, MS 39762, USA, Tel: +1-(601)-325-1291; Fax: +1-(662)325-1031; E-mail: Lora@cvm.msstate.edu

\begin{abstract}
Anthropogenic factors seriously affect water quality and adversely affect fish populations. Agricultural run-off accumulates in the Mississippi River and the coastal estuaries. Alligator gar (Atractosteus spatula) inhabits these waters and is impacted by agricultural pollution, petrochemical contaminants and oil spills. These fish are bimodal air breathers, and use a primitive lung as an accessory organ. The gas bladder, or Air Breathing Organ (ABO) of alligator gar (Atractosteus spatula), is a vascularized air sac located dorsal to the body lumen. It has characteristics of amphibian lungs. Alligator gar air-breathing organs function to supplement branchial respiratory exchange with aerial gas exchange. The alligator gar gas bladder is an elongated air sac that originates dorsal to the pharynx. Air enters through a pharyngeal-esophageal duct that is controlled by two glottal ridges. The pharyngeo-esophageal duct is approximately $5 \mathrm{~mm}$ long and is lined by ciliated columnar epithelium that is continuous with the central canal epithelium. The gas bladder has a central canal that subdivides the bladder into right and left lobes. Each lobe is further divided by septa into series of air spaces. The septa consist of blood vessels and smooth and striated muscles. Air circulates throughout the central canal, lobes and air spaces. The thickness of the septa is determined by underlying, supportive striated muscle. The internal surface of the gas bladder is a continuous respiratory epithelial layer that includes mucus cells, pneumocytes, and ciliated epithelial cells. An understanding of the normal tissue characteristics of this air breathing organ provides a baseline for studying the effects of environmental toxins on this organ.
\end{abstract}

Keywords: Alligator gar; Atractosteus spatula; Air breathing organ, Gas bladder; Pharyngeo-esophageal duct

\section{Introduction}

Alligator gar, Atractosteus spatula, is member of the Infraclass Holostei. This group includes primitive fish and is phylogenetically placed between the chondrosteans and the teleosts [1]. Holostei arose around 180 million years ago $[2,3]$, and includes the orders Amiiformes, the bowfin, and Lepisosteiformes, the gars. These fish have not been well studied [4]. Gars occur in North and Central America, as well as in Cuba. The alligator gar is the largest of the gars (nearly 3 meters maximally) [5]. Within the order Lepisosteiformes, the family
Lepisosteidae includes the genera Atractosteus and Lepisosteus. Atractosteus includes A. spatula (alligator gar), A. tristoechus (Cuban gar), and A. tropicus (tropical gar), while Lepisosteus includes L. oculatus (spotted gar), L. osseus (long nose gar), L. platostomus (short nose gar), and L. platyrhincus (Florida gar) $[2,6,7]$. Atractosteus are distinguishable from Lepisosteus by shorter, more numerous gill rakers and a more prominent second row of teeth in the upper jaw [2]. Atractosteus spatula are distributed in lakes, rivers and estuaries along the coast of the northern Gulf of Mexico [3,8,9]. Currently, estimated gar numbers and fishing regulations vary by state. In Louisiana, alligator gar numbers have decreased [5].

Air breathing fishes occur in fresh and salt water [1] and their aquatic habitats range from desert to tropical rain forest. Amphibians evolved to breathe air while inhabiting aquatic or terrestrial environments. In contrast, bimodal air breathing fish evolved to breathe by exchanging gases from the water and the atmosphere [1], while inhabiting water. Obligatory air breathing fishes use only aerial gas exchange and bimodal air breathing fishes use primarily aerial gas exchange [10-13]. Bimodal and obligatory air breathers can utilize branchial and Air Breathing Organ (ABO) respiration simultaneously [1]. Gars are bimodal air breathing fish that use their gas bladder as a respiratory organ to extract oxygen from the atmosphere [1], especially in hypoxic environments [14]. Fish gills have a large surface area and are in direct contact with the environment. They have important functions including respiration, ion regulation, excretion of nitrogenous waste, and gas exchange [15-18]. Gill surface areas and lamellar thickness are reduced in air breathing fishes in comparison to non-air breathing fishes, but still function for both 02 uptake and most of CO2 excretion [19-22].

The gas bladder of air breathing fish has histological features of amphibian lungs [23,24]. Although the fish ABO and amphibian lungs function similarly, these two organs develop ontogenetically from different tissues [25]. Embryologically, the gas bladder originates from the pharyngeo-esophageal area as a dorsal diverticulum of the esophagus and is joined to the esophagus by the pneumatic duct $[26,27]$. This duct remains 
in fish with a physostomous air bladder, but is absent in adult fish with a physoclistic air bladder [28]. There is controversy surrounding the presence or absence of a pneumatic duct in lepisosteid fish (reviewed in [29]. The bladder itself contains numerous septa that provide a large vascularized area for gas exchange [30]. There is also abundant smooth and skeletal muscle throughout the gas bladder. It is attached to the body wall by dorsal retractors, allowing for contraction.

Most studies on the physiology of gars have utilized Lepisosteus species $[1,30]$. Such studies confirm the function of the bladder in oxygen uptake and carbon dioxide release and its necessity when fish are in hypoxic waters $[1,14,22]$. Similar functions and presumably physiology are seen in Atractosteus spatula $[1,31]$.

Alligator gar is exposed to petrochemical pollutants and agricultural runoff because of the environments they inhabit. Furthermore, as top predators they can bio accumulate pollutants. Alligator gar were evaluated in our studies following the Gulf of Mexico oil spill [32,33].To our knowledge, the fine structure of the alligator gar air breathing organ has not been documented. The purpose of this study was to histologically describe the alligator gar ABO using light and electron microscopy. Knowledge of this organ is necessary to evaluate the effects of pollutants on alligator gar. The ABO is the focus of our on-going studies of this unusual fish.

\section{Materials and Methods}

\section{Animals}

Nine alligator gar were obtained from the Private John Allen National Fish Hatchery in Tupelo, MS, and held in fresh water at the Mississippi Agriculture and Forestry Experiment Station, South Farm Aquaculture Unit, following published methods [34].When sampled, the fish weighed 318 to $320 \mathrm{gm}$ and measured 425 to $430 \mathrm{~mm}$ in length. For tissue collection, each fish was placed in an overdose of anesthetic $(500 \mathrm{mg} / \mathrm{L}$ tricaine methanesulfonate). The gills, body wall and other viscera were removed for analysis of the pharyngeo-esophageal junction. The MSU Institutional Animal Care and Use Committee (IACUC) approved fish holding and experimental protocols.

\section{Light microscopy}

Samples were rinsed in physiological saline and fixed in phosphate buffered $10 \%$ formalin. Tissues were processed and embedded in paraffin, sectioned at $4 \mu \mathrm{m}$, and stained with hematoxylin and eosin (H\&E) and Alcian blue stain. Immunohistochemistry for smooth muscle actin was performed on sections using a Dako Autostainer using a biotinylated streptavidin antibody detection system (Dako LSAB2) with DAB chromogen and hematoxylin counterstain. A monoclonal mouse, anti-human smooth muscle actin primary antibody was used (Dako Clone 1A4, code M0851, 1:100 dilution) and for a negative control, mouse IgG1 was used. Deparaffinization was followed by hydration (1x Tris $\mathrm{pH}$ 6.0) for 5 minutes, then steamed for 30 minutes (antigen retrieval), with subsequent automated processing with primary antibody, and DAB chromogen. Slides were then rinsed in deionized water, dipped in $0.3 \%$ ammonia hydroxide, rinsed again in deionized water, dehydrated through graded alcohol, stained with hematoxylin and eosin, and cover slipped. Slides were viewed under light microscopy on an Olympus BX 51 (Olympus America Inc.) and photographed using Picture Frame ${ }^{\mathrm{TM}}$ software.

\section{Transmission Electron Microscopy (TEM)}

Samples were primarily fixed in $2 \%$ glutaraldehyde in cacodylate buffer $(0.1 \mathrm{M}$ phosphate buffer, $\mathrm{pH} 7.2)$ and then post fixed in $2 \%$ osmium tetroxide at $4^{\circ} \mathrm{C}$. Samples were dehydrated in solutions of increasing ethanol concentration from 35\% to $100 \% \mathrm{ETOH}$, and then in solutions of increasing acetone concentration. Finally, samples were embedded in Spurr's resin. Ultra-sections were made from each block using a Reichert Jung ultra-microtome and stained with toluidine blue stain for thick sections or uranyl acetate and lead citrate for the ultra-thin sections $[35,36]$. All sections were viewed under transmission electron microscopy on a JEOL JEM-1230 at $80 \mathrm{kV}$.

\section{Results}

\section{Gross Morphology}

The alligator gar gas bladder is a large, dorsoventrally flattened, elongate organ that is intimately associated with the musculoskeletal tissues of the dorsal coelom along its entire length and width (Figure1 A, G). The bladder originates at the abrupt termination of the pharyngeo-esophageal duct (Figure $1 \mathrm{D}$, asterisks) and is attached to the body wall by paired slender collagenous folds that run along its entire length on either side of the vertebral column, blending into the stroma that invests the aorta and cardinal veins associated with the mesonephros (Figure 1G). The width of the gas bladder is proportional to the width of the body, tapering and terminating at the end of the coelom (Figure $1 \mathrm{~A}, \mathrm{~B}$ ).

The pharyngeo-esophageal opening arises from the caudal pharynx between the epi pharyngeal teeth, extending caudally to the junction where pharyngeal mucosa blends into esophageal mucosa. It begins anteriorly as a single longitudinally oriented, slit-like opening between the pharyngeal dental pads and extends into the proximal esophagus (Figure 2A). It is delimited by symmetrical fibrous lateral glottal ridges that initially form not only the slightly protruding lips of the slit but also define the shape of the pharyngeo-esophageal duct lumen caudally, a circumscribed tube (Figure2C) which is laterally delimited by the same glottal ridges and lined by ciliated columnar epithelium (Figure $2 \mathrm{~B}, \mathrm{C}$ ). The distance between the termination of the slit aperture and the beginning of the gas bladder, the pharyngeoesophageal duct, averaged $5 \mathrm{~mm}$ in our specimens and was comprised of a tubular structure lined by epithelium and surrounded by a complete investment of soft tissue (duct). The duct continues caudally past the slit as a discrete tubular lumen, terminating immediately as the lumen opens into a spacious gas bladder (Figure 1D, E, F, G). Grossly, the surface margins of the slit are similar to the surrounding mucosa, being slightly thickened and blending imperceptibly into them. The alligator gar gas bladder lies caudal to the abrupt termination of the glottal ridges. 
Grossly, the bladder's rich vascular supply can be easily appreciated with finely arborescent vessels throughout, except for a narrow midline strip of poorly vascularized tissue running along its ventral length (Figure 1A, B). This strip delineates a continuous median central canal that divides the organ into symmetrical halves (Figure 1A, B, and F). The roof and the floor of this central canal are delicate, flat, fibrous membranes. The roof blends into the fibrous raphe that attaches the organ to the aorta (Figure 1G).

Each half of the gas bladder is subdivided by smoothly interconnected, progressively finer and shorter septa forming

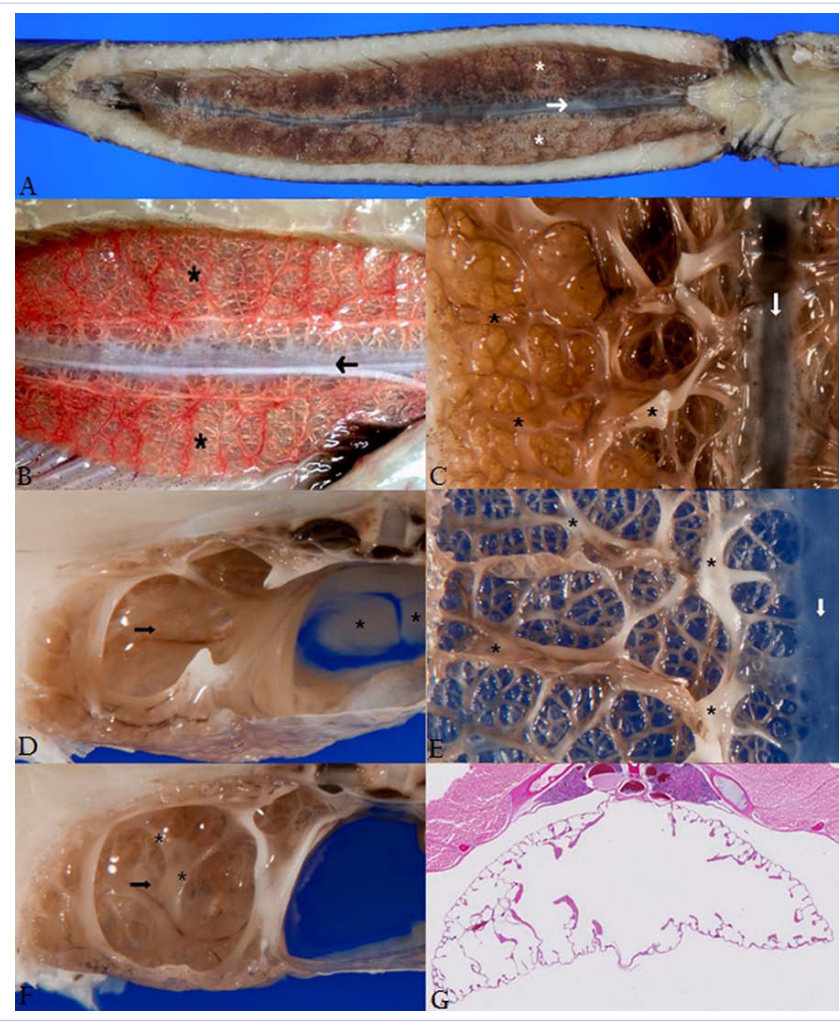

Figure 1: Atractosteus spatula. A: Ventro-dorsal view of the air-breathing organ ( $\mathrm{ABO}$ ), with gills, body wall, and other viscera removed. The head is to the right. Arrow indicates the central lumen, asterisks indicate the air exchange fields. Formalin fixed specimen. B: Ventro-dorsal view of the $\mathrm{ABO}$, fresh specimen, and head is to the right. Arrow and asterisks denote features similar to that in A. C: Ventro-dorsal view of the $A B O$, with the ventral half of the organ removed. Head is to the top of the page. Arrow denotes the central canal, dorsal aspect. Asterisks denote primary and secondary septa. Formalin fixed specimen. D: Caudo-rostral view of the $\mathrm{ABO}$, transversely sectioned approximately $2 \mathrm{~cm}$ from the end of the pharyngeo-esophageal duct. Asterisks denote the termination of the glottal ridges, arrow indicates the gas exchange surface. Dorsum is at the top of the page. Formalin fixed specimen. E: Dorso-ventral view of the ventral half of the $\mathrm{ABO}$, with the dorsum removed (opposite portion of the organ compared to $\mathrm{C}$ ). Arrow denotes the floor of the central canal. Asterisks denote primary septa. Formalin fixed specimen. F: Caudo-rostral view of the $\mathrm{ABO}$, transversely sectioned; left lobe (arrow), septa (asterisks), the central canal is completely opened in comparison to figure D. Formalin fixed specimen. G: Photomicrograph of a transverse section of the entire $\mathrm{ABO}$, dorsum towards the top. Hematoxylin and eosin.

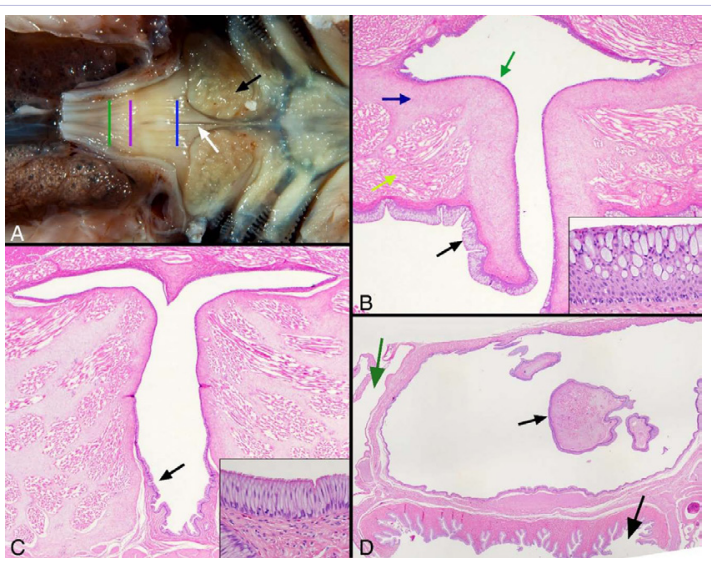

Figure 2: Atractosteus spatula, pharyngeo-esophageal duct. A: Gross view of the dorsum of the pharyngeo-esophageal junction, head is to the right, esophagus transected at the left, the ventral portion of the organ removed. Blue line indicates the level of sectioning shown in B. Purple line indicates the level of sectioning shown in C. Green line indicates the level of sectioning shown in D. Formalin fixed specimen. B: Photomicrograph, transverse section of pharyngeo-esophageal slit denoted by blue line in figure A. A slit-like opening lined by a thick transitional epithelium (black arrow and inset) connects the gut lumen (bottom) to the beginning of the duct (top, green arrow). The glottal ridges are denoted by the green, blue, and yellow arrows, which point to the epithelium, connective tissue stroma, and muscle bundles, respectively. Hematoxylin and eosin, $20 \mathrm{x}$. C: Photomicrograph, transverse section of pharyngeoesophageal duct denoted by purple line in figure $\mathrm{A}$. The inner aspect is lined by a tall simple to pseudostratified columnar epithelium (black arrow and inset). The lumen is surrounded on all sides by thick myocollagenous stroma. Hematoxylin and eosin, $20 \mathrm{x}$. D: Sub gross photomicrograph, transverse section of pharyngeo-esophageal duct denoted by green line in figure $\mathrm{A}$, at the duct termination. The small black arrow indicates the termination of the glottal ridges, as seen in figure $1 \mathrm{D}$, asterisks. A ring of skeletal muscle and tracts of smooth muscle delimit the duct. The large black arrow denotes the esophagus, the green arrow denotes the air bladder proper, hematoxylin and eosin.

first, second, third, and fourth order alveolar chambers (Figure 1C, E, G). Septa tend to have abrupt bulbous terminations composed of dense stroma (Figure 3B). The central canal is laterally delimited by the primary septa, forming an arcade of regular pillars with wide intervening ostia that lead into the gas exchange spaces. The progressing septal order divisions often form oblique angles, with a reduction in septal height by approximately half, finally terminating in low alveoli approximately 1 millimeter wide (Figure 1C, E).

\section{Microscopic Morphology and Ultra structure}

In the glottis and pharyngeo-esophageal duct, the pharyngeal mucosa is stratified columnar epithelium that varies in thickness from 100 to 200 micrometers and predominantly contains large mucus cells (Figure 2B, C). The glottal ridges are the protruding lips of mucosa that guard the entrance to the pharyngeo-esophageal duct. Anteriorly on transverse section, the duct forms a "T" where a 2 to 3 millimeter long stem dorsally meets a collapsed tubule forming the bar of the "T" (Figure 2B). Progressing caudally as the slit opening ends (Figure 2C), the duct continues to meet the gas bladder proper. 
Anteriorly, pharyngeal mucosa lines the duct. Initially, a ciliated stratified columnar epithelium (esophageal type) appears in the stem of the duct, becoming the predominant cell type caudally as the duct becomes detached from the ventral esophagus and eventually entirely lining the duct (Figure. 2B, C, D).

In the alligator gar pharyngeo-esophageal duct, a thick cushion of mucinous areolar connective tissue containing evenly spread, fine collagen fibrils with plump stellate mesenchymal cells supports the duct mucosa's (Figure. 2B and C). Subjacently, this stroma blends into dense fascicles of skeletal muscle admixed with small nerves and vessels. A thin layer of transverse and obliquely arranged skeletal muscle bundles overlie the dorsum of the duct where it abuts the vertebral column, along with symmetrical, anteroposteriorly arranged thick muscle bundles (dorsal retractors).

The floor of the central canal and ventral aspects of the primary septa are lined by a stratified to pseudo stratified, ciliated columnar epithelium with a prominent mucus cell component. The mucus cells contain PAS (not shown) and Alcian blue positive content, consistent with acid mucopolysaccharide (Figure 3I).

Progressing from first to fourth order septa, the epithelium gradually thins, with eventual loss of ciliated cells, giving way to a simple squamous epithelium covering capillaries and relatively few, evenly spaced, attenuated mucus cells (Figure 3C, D, E). This progression continues with eventual loss of mucus cells in the respiratory exchange surface (respiratory epithelium) (Figure 3E, F, G) (Figure 5A). This progressive epithelial change also occurs centrally to the periphery, where respiratory epithelium covers all alveolar surfaces; typical pneumocytes occur here. The respiratory surface is covered by irregular microvilli on squamous cells (Figure 4A, B, C). Electron micrographs demonstrate that squamous cells contain numerous lamellar bodies with stacked content (Figure 4C). Intercellular connections are composed of tight junctions and desmosomes with marked invagination of both adjacent cell membranes. Nuclei are irregular with a distinct thin rim of heterochromatin, abundant euchromatin, and prominent nucleoli (Figure 4A, B, C) (Figure 5A).

Mucus cell content was hyper chromatic (Figure 4 A, B, C). Mucus cells lining alveoli and septal walls included occasional Neuroendocrine cells (NE) either between cells or along the basal aspects (Figure 4A). Neuroendocrine cytoplasm contained many dense uniform granules approximately $100 \mathrm{~nm}$ wide. Occasionally, NE cells were present in small tightly packed groups associated with nerves (Neuroepithelial Bodies-NEBs).

The central canal, septa, and alveoli consist of a similar sub epithelial stroma, composed of a thin layer of densely packed collagen fibers with fibroblasts and small blood vessels. The bulk of the septa, in particular the bulbous terminae, are composed of densely packed, irregularly arranged fascicles of striated skeletal muscle (Figure 3I). Smooth muscle is also prominent, investing septal skeletal muscle bundles with particular prominence

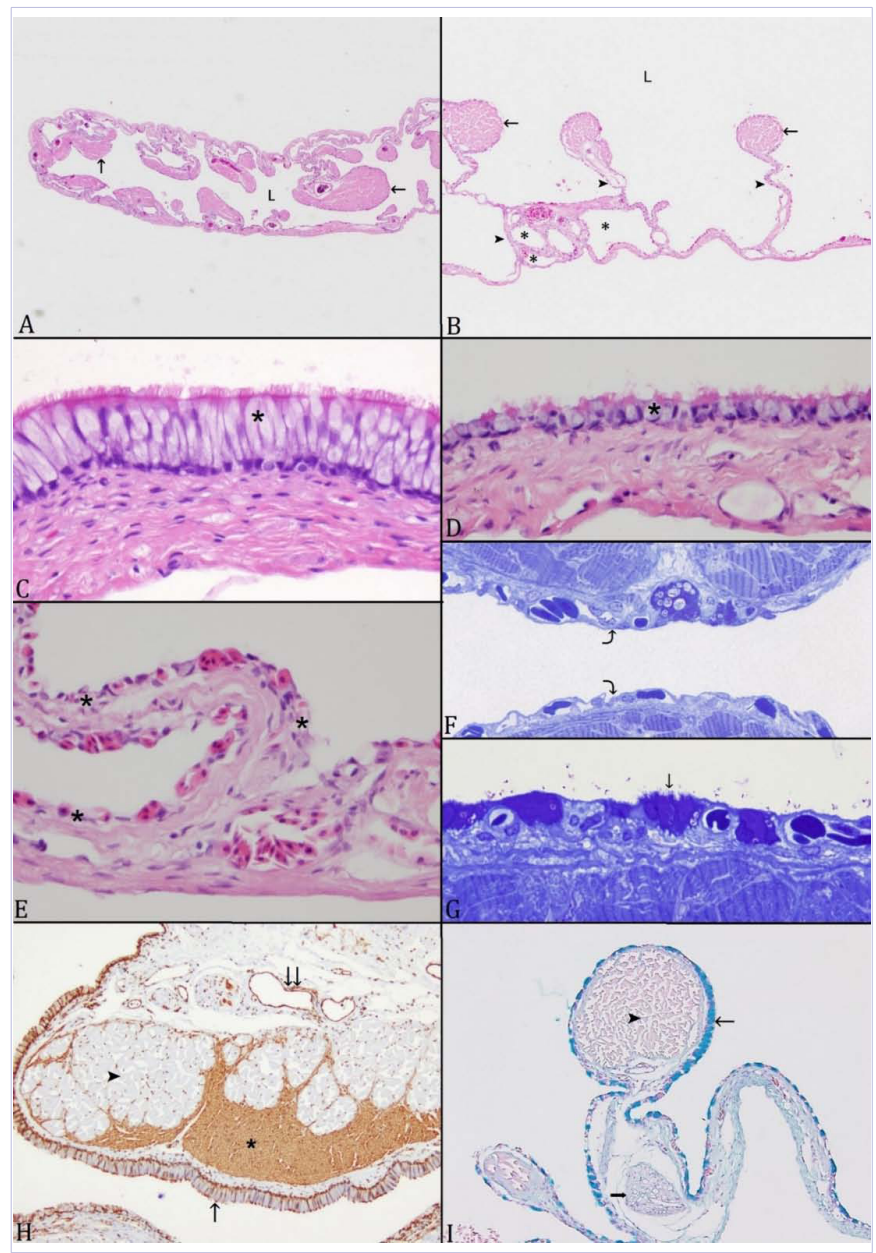

Figure 3: Multiple views of Atractosteus spatula. A: An overview of the left lobe shows the lumen and septa. Septa are composed of striated muscles, blood vessels, and forms bundles (arrow) that are projecting toward the lumen; lumen (L). B: Each lobe is subdivided into different levels of air spaces (asterisk) by series of septa (arrowhead); bundles of striated muscle are in the apical portion of septa (arrow). $\mathbf{C}$ and D: The internal surface is lined by a stratified to pseudostratified, ciliated columnar epithelium with prominent mucus cell components (asterisk). E: The internal surface gradually changes to simple squamous epithelium rich with blood vessels (asterisk) (curved arrow).F: resin toluidine blue stain section showing the same G:Simple squamous epithelium rich with blood vessels with few, evenly spaced, attenuated mucus cells (arrow); resin toluidine blue stain section. H: Cross section stained with smooth muscle actin stain; smooth muscle (asterisk) is highlighted by the antigen, and interdigitates with striated muscle (arrowhead); veins are also lined by smooth muscle (double arrow). The internal surface is lined by a stratified to pseudostratified, ciliated columnar epithelium with prominent mucus cells components (arrow). I: Mucus cells contain Alcian blue positive content (thin arrow), striated muscles (arrowhead); nerve fiber (thick arrow); (Alcian Blue stain).

along their proximal aspects (Figure 3H). Unlike skeletal muscle, smooth muscle is present throughout the stroma at all levels and in general, forms delicate fascicles and individualized cells that admix with connective tissues. Muscle content gradually decreases caudally and peripherally.

Vessels, nerves, and unmyelinated axons run along the 
apical portions of the septal terminae, typically subjacent to the muscle bundles (Figure. 3A, B, F, G, I) (Figure. 4A, D) (Figure. 5C). Capillaries are regularly nestled between epithelial cells and are covered apically by thin extensions of epithelial cells, forming an air-blood barrier approximately 1 micron thick (Figure. 4A, B). The endothelium is continuous, overlying a collagenous lamina. Endothelial nuclei are located away from the surface and have irregular nuclei with rims of heterochromatin (Figure. $4 \mathrm{~A}, \mathrm{~B})$. Within the delicate stroma of the floor of the central cavity, regular paired ganglia travel along the length of the organ bilaterally. Progressively smaller nerves without neurons are present in the septa as they become finer. There are few small, random aggregates of lymphocytes that surround blood vessels and encroach on the epithelium with occasional areas of epithelial intercellular migration.

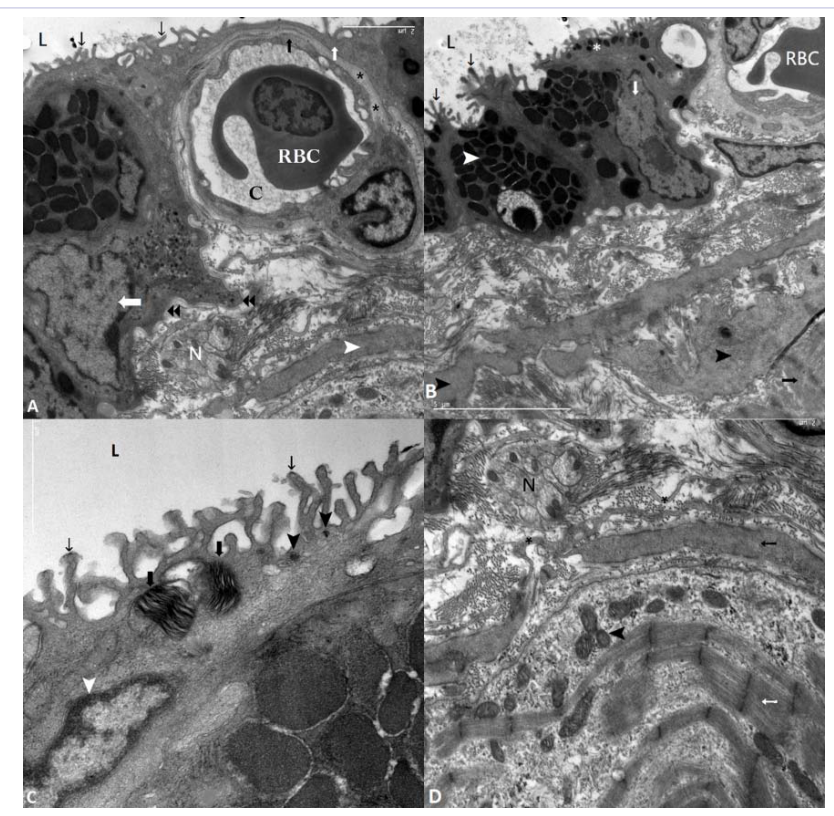

Figure 4: Atractosteus spatula; Transmission electron micrographs of the gas bladder. A: The capillary barrier in the respiratory epithelium consists of an outer microvillus border (thin black arrow) with a thin cytoplasmic layer (thin white arrow), overlying a capillary (C) with a continuous endothelial lining (black arrow) and interstitial layer in between (asterisks).A red blood cell (RBC) is present in the lumen. The thin white arrowhead indicates smooth muscle with filament bundles. A nerve fiber $(\mathrm{N})$, and a neuroendocrine cell (delimited by black arrowheads and thick white arrow indicates nucleus) are present. B: The gas bladder epithelium includes mucus cells (white arrowhead) and epithelial cells with numerous microvilli (thin black arrow); mucus nuclei (white arrow). L denotes the lumen. A Red Blood Cell (RBC) is in the capillary. Multi lamellar bodies (white asterisk) are located in the apical part of the respiratory epithelium. Smooth muscle cells (black arrowheads), and striated muscle (black arrow) are present within a loose collagenous stroma. C: The apical region of the epithelium includes multi lamellar bodies (thick arrows), lumen (L), dense bodies (black arrowheads), microvilli (thin black arrows), and a pneumocyte nucleus (white arrowhead). D: (Overlapping field with A) The lamina propria is composed of loose collagenous stroma populated by smooth muscle (black arrow) and striated muscle (white arrow) with prominent mitochondria (arrowhead). Nerves $(\mathrm{N})$ are separated from the other components by fibroblast extensions (asterisk).

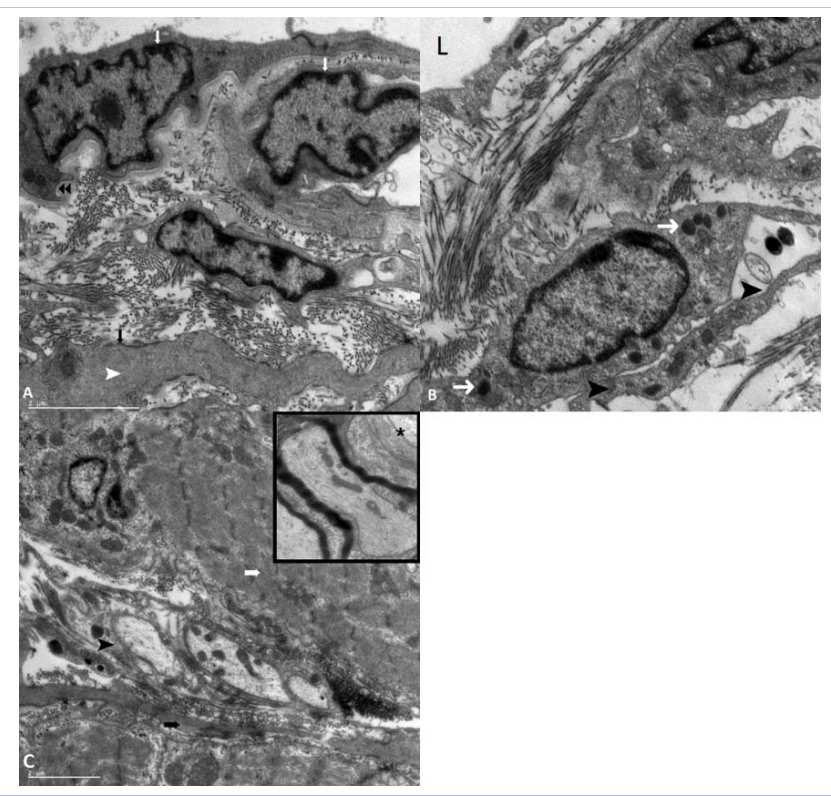

Figure 5: Alligator gar; transmission electron microscope (TEM) micrographs of the $\mathrm{ABO}$. A: The white arrows indicate the pneumocyte nucleus adjacent to the border of the epithelium. The double arrow heads indicates the basal cytoplasmic extension just beneath them. Filament bundle of smooth muscles (white arrowhead) show sub plasmalemmal condensations (black arrow). B: This TEM micrograph shows the neuroendocrine cell with dense bodies/granules (white arrow) in its cytoplasm, and the neuroendocrine is embraced with an extension of fibroblast (black arrowhead). Lumen (L). C: Unmyelinated axons (arrowhead) located between smooth muscles (black arrow) and striated muscles (white arrow). The inset (TEM micrograph under higher magnification) shows the unmyelinated axons that are embraced by the fibroblast (asterisks).

\section{Discussion}

In air breathing fish, the general description of the gas bladder, or $\mathrm{ABO}$, is an unpaired oval elongated structure arising from the posterior side of the pharynx and connected to the pharynx. It is located dorsal to the body lumen and consists of a central canal that occupies a third of the gas bladder and two lobes that are covered with a very thin tissue wall $[1,3,22,24,25,37]$. Our findings in alligator gar were similar. The gas bladder was a large elongate organ with progressively finer and shorter septa forming first, second, third, and fourth order alveolar chambers and a central canal. The gas bladders of other air breathing fish are also described to have trabeculae dividing the gas bladder into compartments and a central canal $[1,30]$. The alligator gar gas bladder is medially divided into two alveolate portions by a central canal lined by abundant ciliated epithelium, similar to bowfins and other gar species $[24,29,38]$. The location and abundance of ciliated cells suggests that these tissues function as a pulmonary escalator and move cell and foreign debris to the duct and then out into the pharynx.

Numerous mucus cells and surfactant bodies were identified in the respiratory epithelium, similar to that seen in L. oculatus [24]. The mucus content in mucus cells was an acid mucopolysaccharide, similar to that seen in non-respiratory 
airway surfaces in reptiles and mammals. Microvilli were abundant on the gas bladder surfaces of A. spatula, as was a secreted mucus barrier. We believe the functions of the microvilli, or ciliated cells, was to secrete mucus to protect the internal surface of the gas bladder as has been suggested in other gar [39].

Throughout the organ, smooth and skeletal muscle fascicles were abundant, giving strength to this delicate, well-vascularized organ. The muscle fascicles were often intimately associated with one another. The intermediate layer of the Lepisosteus gas bladder was described to consist of striated muscle, smooth muscle, fibroblasts, and elastic fibers [22]. We observed nerve bundles in the connective tissue of the alligator gar gas bladder. These findings were also reported in the spotted gar gas bladder [24]. Nerve fibers were also found in the walls of the ABO of bichir and gars [40, 41].

The nature of the opening to the gas bladder is debated in gars [24,29]. It has been anatomically described in multiple Lepisosteus species $[1,24,29,38]$. There is one brief description of a pneumatic duct in Atractosteus tristoechus [42]. Recent work in L. oculatus and L. osseus conclude that, in Lepisosteus, the alimentary canal opens into the gas bladder through a slitlike opening and that a discrete tubular structure, or "duct" is lacking $[24,29]$. In our study, we found that alligator gar have a pharyngeo-esophageal duct. It is anteriorly delimited by a slit-like opening and a slender aperture that continues as an epithelium lined lumen within a tubular structure circumscribed by connective tissue. This location is similar to the gas bladder opening described in L.oculatus, [24]. Unlike L. osseus, in which the gas bladder gradually widens from a narrow anterior point, the gas bladder in A. spatula begins where an abrupt termination of the glottal ridges of the pharyngeo-esophageal duct opens into a fully dilated, alveolated gas bladder with squamous respiratory epithelium. This epithelium is continuous with the central canal of the gas bladder. The glottal ridges of A. spatula are similar to those described in L. oculatus and L. osseus [24,29]. The presence of robust paired dorsal retractor muscles is also similar, and may control the size of the glottal opening.

In Lepisosteus, the interior surface of the respiratory epithelium is ciliated and lined with lamellar bodies and goblet cells [22]. In mammals, respiratory alveolar surfaces are lined by type I and type II pneumocytes. Type I cells are simple squamous cells, and type II cells are cuboidal [43-46]. Type II cells are associated with surfactant production and retain the capacity to divide, functioning as a source for new type I cells. Our study suggests that Atractosteus have one type of pneumocyte that probably combines the functions of mammalian type I and II pneumocytes. This pneumocyte was similar to the amphibian pneumocyte described by Pastor [46]. Amphibians, Dipnoi (lungfish), and L. oculatus also have one type of pneumocyte [46]. We observed some pneumocytes that appeared to have cytoplasmic processes. Similar cells were seen in the respiratory epithelium of amphibians [47-49]. Neuroepithelial cells occur between the pneumocytes and goblet cells in amphibians and Lepisosteus $[37,46]$.
In alligator gar, we observed that Neuroendocrine Cells (NECs) are located between epithelial cells and also between the mucus cells and ciliated cells in the respiratory epithelial cells as Neuroepithelial Bodies NEBs. Similar results were observed in spotted gar and long nose gar $[24,38]$. The presence of neuroendocrine cells suggests neuronal control of the gas bladder $[37,38]$.

The internal surface of the alligator gar gas bladder is rich in ciliated cells that are irregular in shape and project toward the lumen of the gas bladder. These ciliated cells reduce the area available for respiratory exchange. Similar distribution of these ciliated cells has been observed in spotted gar and amphibians $[24,48,50]$.

Alligator gar neuroendocrine cells were similar to those observed in the ABO of other gars. Neuroendocrine Cells (NECs) were pyramidal and occurred in the basal portion of the respiratory epithelium. These cells were characterized by the presence of dense secretory granules, Golgi bodies, rough endoplasmic reticulum, and scattered numbers of mitochondria in the basal part of the cell [46]. The presence of neuroendocrine cells in the gas bladder indicates endocrine and paracrine control over bladder function $[37,38,46]$. Neuroepithelial bodies and NEs are surrounded and invested by ciliated cells, goblet cells, and pneumocytes $[37,38,46]$.

The alligator gar air breathing organ is a single air sac that emerges from the dorsal margin of the foregut, while amphibian lungs are paired organs that emerge from the ventral margin of the foregut $[25,48]$. There are many similarities in the anatomy and histology of the gar $\mathrm{ABO}$ and amphibian lungs [24].The alligator gar $\mathrm{ABO}$ has a series of air spaces similar to the lung but it lacks the bronchial tree that is observed in lungs [51,52]. The structure of the alligator $\mathrm{ABO}$ is very similar to the $\mathrm{ABO}$ of the genus Lepisosteus. Alligator gar inhabits coastal estuaries that are prone to agricultural and petrochemical pollution. One study reported that Atractosteus tropicus and Lepisosteus oculatus had higher tissue PCB concentrations than other fish in waters that had low, acceptable levels of contaminants [53]. Therefore, these fish are an excellent sentinel model for studying the effects of pollutants on aquatic ecosystems.

\section{References}

1. Graham J B. Air-breathing fishes: evolution, diversity, and adaptation. San Diego, Academic Press. 1997.

2. Wiley E O. The phylogeny and biogeography of fossil and recent gars (Actinopterygii; Lepisosteidae). University of Kansas, Museum of Natural History, Miscellaneous Publication. 1976;64:1-111.

3. Suttkus, R.D. Order Lepisostei. In Bigelow, H. B., and W. C. Schroeder, editors. Fishes of the western North Atlantic. Order Lepisostei 1963: Memoirs of the Sears Foundation for Marine Research 1, Part 3. New Haven, Connecticut. P. 61-88.

4. Wright P A. Ionic, Osmotic, and Nitrogenous Waste Regulation. Fish Physiology. 2007;26:283-318.

5. Mendoza Alfaro R, C A González, A M Ferrara. Gar biology and culture: status and prospects. Aquaculture research. 2008;39(7):748-763. 
6. Etnier, D.A. and W.C. Starnes, The fishes of Tennessee. University of Tennessee Press-Knoxville, $1^{\text {st }}$ ed 1993.

7. Cavin L. Diversity of Mesozoic semionotiform fishes and the origin of gars (Lepisosteidae). Naturwissenschaften, 2010;97(12):1035-1040.

8. Page L M, B M Burr. A field guide to freshwater fishes: North America north of Mexico. Peterson field guide series: 42. Boston: Houghton Mifflin. 1991.

9. Ross S T. The Inland Fishes of Mississippi. By Stephen T Ross. The Quarterly Review of Biology, 2001;77(4): 469-470.

10. Moraes M F, S Holler O T F Costa, M L Glass, M N Fernandes S F Perry. Morphometric comparison of the respiratory organs in the South American lungfish Lepidosiren paradoxa (Dipnoi). Physiol Biochem Zool, 2005;78(4):546-559.

11. Hughes G M, B R Singh, G Guha, S C Dube, J S Datta Munshi. Respiratory surface areas of an air-breathing siluroid fish Saccobranchus (Heteropneustes) fossilis in relation to body size. Journal of Zoology, 1974;172(2):215-232. 10.1111/j.1469-7998.1974.tb04103.x.

12. Perna S A, M N Fernandes. Gill morphometry of the facultative air-breathing loricariid fish, Hypostomus plecostomus (Walbaum) with special emphasis on aquatic respiration. Fish Physiology and Biochemistry. 1996;15(3):213-220.

13. Mazon A F, M N Fernandes, M A Nolasco, W Severi. Functional morphology of gills and respiratory area of two active rheophilic fish species, Plagioscion squamosissimus and Prochilodus scrofa. Journal of Fish Biology. 1998;52(1):50-61. doi: 10.1111/j.1095-8649.1998. tb01552.x.

14. Smatresk N J, J N Cameron. Respiration and acid-base physiology of the spotted gar, a bimodal breather. I. Normal values, and the response to severe hypoxia. Journal of Experimental Biology. 1982;96:263-280.

15. Perry S F. Relationships between branchial chloride cells and gas transfer in freshwater fish. Comp Biochem Physiol A Mol Integr Physiol. 1998;119(1):9-16.

16. Dymowska A K, PP Hwang, G G Goss. Structure and function of ionocytes in the freshwater fish gill. Respir Physiol Neurobiol. 2012;184(3):282-92. doi: 10.1016/j.resp.2012.08.025.

17. Hwang PP. Ion uptake and acid secretion in zebrafish (Danio rerio). J Exp Biol. 2009;212(Pt 11):1745-52. doi: 10.1242/jeb.026054.

18. Roberts R J. Fish Pathology. 3rd ed. London; New York: W B Saunders; 2001.

19. Fullarton M H. Notes on the Respiration of Lepidosiren. Journal of Zology. London. 1931;101(4):1301-1306.

20. Tamura O, T Moriyama. On The Morphological Feature of The Gill of Amphibious and Air Breathing Fishes. Bull. Fac. Fish. Nagaski Univ. 1976;41:1-8

21. Roy P K, J S D Munshi. Morphometrics of the respiratory organs of a freshwater major carp, Cirrhinus mrigala in relation to body weight. Japan. J. Ichthyol. 1986;33:(3)269-279.

22. Potter G. Respiratory function of the swim bladder in Lepidosteus. Journal of Experimental Zoology. 1927;49:45-67. D0i: 10.1002/ jez.1400490103.

23. Kapoor B G, B Khanna. Ichthyology handbook / B G Kapoor, Bhavna Khanna. Berlin; New York; Springer; New Delhi: Narosa Pub. House. 2004.

24. Icardo J M, E Colvee, E R Lauriano, G Capillo, M C Guerrera, G Zaccone. The structure of the gas bladder of the spotted gar, Lepisosteus oculatus. J Morphol. 2015;276(1):90-101. doi: 10.1002/jmor.20323.
25. Perry S F, R J Wilson, C Straus, M B Harris, J E Remmers. Which came first, the lung or the breath? Comp Biochem Physiol A Mol Integr Physiol. 2001;129(1):37-47.

26. Morrison C M, T Miyake, JR Wright Jr. Histological study of the development of the embryo and early larva of Oreochromis niloticus (Pisces: Cichlidae). J Morphol. 2001;247(2):172-95.

27.Ünal G, o Cetinkaya, E Kankaya, M Elp. Histological study of the organogenesis of the digestive system and swim bladder of the Chalcalburnus tarichi Pallas, 1811 (Cyprinidae). Turkish Journal of Zoology, 2001;25(3):217-228.

28. Doroshev S I, J W Cornacchia. Initial swim bladder inflation in the larvae of physoclistous fishes and its importance for larval culture. In: Lasker RM, Sherman K (eds) The early life history of fish: recent studies. J Cons int Explor Mer. 1981;178:495-500.

29. Jaroszewska M, K Dabrowski. Morphological analysis of the functional design of the connection between the alimentary tract and the gas bladder in air-breathing lepisosteid fish. Ann Anat. 2008;190(4):38390. doi: 10.1016/j.aanat.2008.01.002.

30. Rahn H, Rahn KB, Howell BJ, Gans C, Tenney SM. Air breathing of the garfish (Lepisosteus osseus). Respir Physiol. 1971;11(3):285-307.

31.Wilder B G. Notes on the North American ganoids Amia, Lepidosteus, Acipenser, and Polyodon, with three plates. Salem, Mass.Proc. Amer. Assoc. Adv. Sci. 1876:24.

32. Omar-Ali A, C Hohn, P J Allen, J Rodriguez, L Petrie-Hanson. Tissue $\mathrm{PAH}$, blood cell and tissue changes following exposure to water accommodated fractions of crude oil in alligator gar, Atractosteus spatula. Mar Environ Res. 2015;108:33-44. doi: 10.1016/j. marenvres.2015.04.011.

33. Ali A O, C Hohn, P J Allen. The effects of oil exposure on peripheral blood leukocytes and splenic melano-macrophage centers of Gulf of Mexico fishes. Mar Pollut Bull. 2014;79(1-2):87-93. doi: 10.1016/j. marpolbul.2013.12.036.

34. Schwarz D E, P J Allen. Effects of salinity on growth and ion regulation of juvenile alligator gar Atractosteus spatula. Comparative Biochemistry and Physiology. A, Molecular \& Integrative Physiology, 2014;169: 4450 .

35. Bozzola J J, L D Russell. Electron Microscopy: Principles and Techniques for Biologists. Sudbury, Mass. Jones, Bartlett. 2nd ed. 1999.

36. Watson M L. Staining of Tissue Sections for Electron Microscopy with Heavy Metals. J Biophys Biochem Cytol. 1958 Nov 25; 4(6):727-730.

37.Zaccone D, K Dabrowski, E R Lauriano. The simultaneous presence of neuroepithelial cells and neuroepithelial bodies in the respiratory gas bladder of the longnose gar, Lepisosteus osseus, and the spotted gar, L. oculatus. Acta Histochem. 2012;114(4):370-8. doi: 10.1016/j. acthis.2011.07.006

38. Zaccone D, M Sengar, E R Lauriano. Morphology and innervation of the teleost physostome swim bladders and their functional evolution in non-teleostean lineages. Acta Histochem, 2012;114(8):763-72.

39. Sperry D G, R J Wassersug. A proposed function for microridges on epithelial cells. Anat Rec. 1976;185(2):253-270.

40. Nilsson S. Nervous control of fish swimbladders. Acta Histochem. 2009;111(3):176-84. doi: 10.1016/j.acthis.2008.11.016.

41.Zaccone G, A Mauceri, M Maisano, A Giannetto, V Parrino, S Fasulo. Innervation and neurotransmitter localization in the lung of the Nile bichir Polypterus bichir bichir. Anat Rec (Hoboken). 2007;290(9):1166-77. 
42. Lukas J. Visceral anatomy of the garpike, Atractosteus tristoechus Folia Zoologica. 1989;38(3):265-274.

43. Burns AR, CW Smith, DC Walker. Unique structural features that influence neutrophil emigration into the lung. Physiol Rev, 2003;83(2):309-36.

44. Penney DP. The ultrastructure of epithelial cells of the distal lung. Int Rev Cytol. 1988;111:231-69.

45. Kuhn C. Ultrastructural and cellular function in distal lung. Monogr Pathol, 1978;(19):1-20.

46. Pastor LM. Histology, ultrastructure and immunohistochemistry of the respiratory organs in non mammalian vertebrates. Zaragoza, Spain: Univ. DE Murcia, Murcia; 1995. 225.

47. Hermida GN, LE Fiorito, A Farias. The lung of the common toad, Bufo arenarum (Anura, Bufonidae). A light and electron microscopy study. Biocell. 1998;22(1):19-26.

48. Hermida GN, A Farias, LE Fiorito, Ultrastructural characteristics of the lung of Melanophryniscus stelzneri (Weyenberg, 1875) (Anura, Bufonidae). Biocell, 2002;26(3):347-55.
49. Fernandes MN, A L da Cruz, O T da Costa, S F Perry. Morphometric partitioning of the respiratory surface area and diffusion capacity of the gills and swim bladder in juvenile Amazonian air-breathing fish, Arapaima gigas. Micron. 2012;43(9):961-70.

50. Connie C W Hsia, Anke Schmitz, Markus Lambertz, Steven F Perry, John N. Maina. Evolution of air breathing: oxygen homeostasis and the transitions from water to land and sky. Compr Physiol. 2013;3(2):849915. doi: 10.1002/cphy.c120003.

51. Frappell P.B, C B Daniels. Ventilation and Oxygen Consumption in Agamid Lizards. University of Chicago Press. 1991;64(4):985-1001.

52.Stark-Vancs V, P B Bell Jr, V H Hutchison. Morphological and pharmacological basis for pulmonary ventilation in Amphiuma tridactylum. An ultrastructural study. Cell and Tissue Research. 1984;238(1):1-12.

53. Carvalho FP, J PVilleneuve, C Cattini, J de Rendon, J M Oliveira. Ecological risk assessment of PCBs and other organic contaminant residues in Laguna de Terminos, Mexico. Ecotoxicology. 2009;18(4):403-16. 